\title{
Determining Performance of Super Critical Power Plant with the help of "GateCycle" TM",
}

\author{
Anooj G. Sheth ${ }^{1}$, Alkesh M. Mavani ${ }^{2}$ \\ 1. Mechanical Engineering (Thermal Engineering) LDRP Institute of Technology \& Research \\ Gandhinagar-382015, India \\ 2. Associate Professor, Mechanical Department, LDRP Institute of Technology \& Research \\ Gandhinagar-382015, India
}

\begin{abstract}
This paper determines the performance of super critical power plant from given performance characteristics of its main components with the help of GateCycle ${ }^{\mathrm{TM}}$ software. The performance characteristics of the standard equipment like Condensers. Steam turbines, Boiler, Pumps etc. have been taken from vendor's catalogues. The predicted performance of the system is seen very close to the original performance.
\end{abstract}

Key Words: boiler, condenser, GateCycle ${ }^{\mathrm{TM}}$, pump, steam turbine, super critical power plant

\section{INTRODUCTION}

The electrical generation and distribution system must reflect responsible application of economic and environmental concerns. The terms "subcritical" and "supercritical" refer to main steam operating conditions being either below or above the critical pressure of water $(22.06 \mathrm{MPa})$ and the temperature is increased above $647^{\circ} \mathrm{K}$. The significance of the critical point is the difference in density between steam and water.

Subcritical plants are reliable but the efficiency of subcritical plants is low and also the emissions with this type of plants are high. However, because of low efficiency and high emissions, these plants have not wide application. The higher pressure of a supercritical cycle results in a higher overall unit efficiency than a sub-critical cycle. The other benefit of super critical power plant is burn less fuel for same output and less emission.

Supercritical coal fired power plants with efficiencies of $45 \%$ have much lower emissions than subcritical plants for a given power output. These include the turbine-generator set, the once-through boiler and operational issues such as load change, fuel flexibility and water flow.

Response to fast load changes of 3-5\% per min compared to $1-2 \%$ for sub critical.

This paper presents the details of a simulation procedure which has been developed for determining performance of a super critical power plant of 700MW.

\section{SYSTEM DESCRIPTION}

As we know that super critical system works at higher pressure and higher temperature than sub critical system its overall efficiency is higher.
For system under consideration the high pressure high temperature steam produced by the boiler is first expanded into the HP ST-1 turbine. The first extraction from HP ST1 is directly send to the FWH7 and the remaining steam from the exhaust is spiltted into two parts, one goes to FWH6 and other goes for reheating in the boiler.

Because of the reheating the steam gains its high temp and pressure again. The steam from the reheater is expanded to the IP ST2 turbine. The steam is extracted from IP ST2 in two stages which go respectively to the FWH5 and deaerator. The exhaust of IP ST2 is again expanded in LP ST3 and LP ST4 turbine. The steam from both low pressure turbines is extracted in three stages. First extractions from LP ST3 and LP ST4 go into FWH4 and FWH3 respectively. The second extraction from both turbines is mixed into the mixer M3 and then goes into the FWH2. And the third extraction from both LP turbines is mixed into the mixer M2 and goes to the FWH1. Remaining stream from LP ST3 and LP ST4 turbines are exhausted and go into the condenser CND2 and CND1 respectively.

The steam is condensed in the condenser by the external cooling water. The water from the condenser CND1 and CND2 is extracted with the help of PUMP1 and PUMP3 respectively. The water from the pump get mixed into the mixer M4 and goes to the FWH1, FWH2, FWH3, FWH4, DA1, PUMP2, FWH5, FWH6 and FWH7.this feed water gets heated by the steam extracted from the turbines LP ST4, LP ST3, IP ST2 and HP ST1. The pump1 works by the work produced by the BFPT ST5. The steam into BFPT ST5 comes from the extraction of IP ST2. And finally feed water from FWH7 goes to the boiler. 
IOSR Journal of Engineering

Apr. 2012, Vol. 2(4) pp: 692-696

III. INPUT PARAMETERS

Table-1Input Data

\begin{tabular}{|c|c|c|}
\hline Equipment & Input Values & Units \\
\hline \multicolumn{3}{|c|}{ Ambient Condition } \\
\hline Temperature & 288 & ${ }^{\circ} \mathrm{K}$ \\
\hline Pressure & 1.032 & Bar \\
\hline \multicolumn{3}{|c|}{ Auxiliary boiler -1} \\
\hline Desired Flow & 2131200 & $\mathrm{Kg} / \mathrm{hr}$ \\
\hline Exit Temperature & 836 & ${ }^{\circ} \mathrm{K}$ \\
\hline \multicolumn{3}{|c|}{ Auxiliary boiler -2} \\
\hline Desired Flow & 1756800 & $\mathrm{Kg} / \mathrm{hr}$ \\
\hline Exit Temperature & 595 & ${ }^{\circ} \mathrm{K}$ \\
\hline \multicolumn{3}{|c|}{$\mathrm{ST}-1$} \\
\hline Exit pressure & 54 & Bar \\
\hline Input pressure & 242 & Bar \\
\hline \multicolumn{3}{|c|}{$\mathrm{ST}-2$} \\
\hline Exit pressure & 12 & Bar \\
\hline Input pressure & 54 & Bar \\
\hline \multicolumn{3}{|c|}{$\mathrm{ST}-3$} \\
\hline Exit pressure & 0.0768 & Bar \\
\hline \multicolumn{3}{|c|}{$\mathrm{ST}-4$} \\
\hline Exit pressure & 0.0983 & Bar \\
\hline \multicolumn{3}{|c|}{ CND - 1} \\
\hline Operating Pressure & 0.0983 & Bar \\
\hline \multicolumn{3}{|c|}{$\mathrm{CND}-2$} \\
\hline
\end{tabular}

\begin{tabular}{|c|c|c|}
\hline Operating Pressure & 0.0768 & Bar \\
\hline \multicolumn{3}{|c|}{ PUMP - 1(CEP-1) } \\
\hline Desired Mass Flow & 784800 & $\mathrm{Kg} / \mathrm{hr}$ \\
\hline Rated Head & 1066 & $\mathrm{~m}$ \\
\hline \multicolumn{3}{|c|}{ PUMP - 3(CEP-2) } \\
\hline Desired Mass Flow & 784800 & $\mathrm{Kg} / \mathrm{hr}$ \\
\hline Rated Head & 1066 & $\mathrm{~m}$ \\
\hline \multicolumn{3}{|c|}{ LP Heater - 1(FWH1) } \\
\hline TTD & 276 & ${ }^{\circ} \mathrm{K}$ \\
\hline \multicolumn{3}{|c|}{ LP Heater - 2(FWH2) } \\
\hline TTD & 276 & $\mathrm{~K}$ \\
\hline \multicolumn{3}{|c|}{ LP Heater - 3(FWH3) } \\
\hline TTD & 276 & ${ }^{\circ} \mathrm{K}$ \\
\hline \multicolumn{3}{|c|}{ LP Heater - 4(FWH1) } \\
\hline TTD & 276 & $\mathrm{~K}$ \\
\hline \multicolumn{3}{|c|}{ PUMP-2(BFP - 1) } \\
\hline Desired Mass Flow & 2145600 & $\mathrm{Kg} / \mathrm{hr}$ \\
\hline Rated Head & 3500 & $\mathrm{~m}$ \\
\hline \multicolumn{3}{|c|}{ HP Heater - 5(FWH5) } \\
\hline TTD & 271 & ${ }^{\circ} \mathrm{K}$ \\
\hline \multicolumn{3}{|c|}{ HP Heater - 6(FWH6) } \\
\hline TTD & 273 & ${ }^{\circ} \mathrm{K}$ \\
\hline \multicolumn{3}{|c|}{ HP Heater - 7(FWH7) } \\
\hline TTD & 271 & ${ }^{\circ} \mathrm{K}$ \\
\hline
\end{tabular}

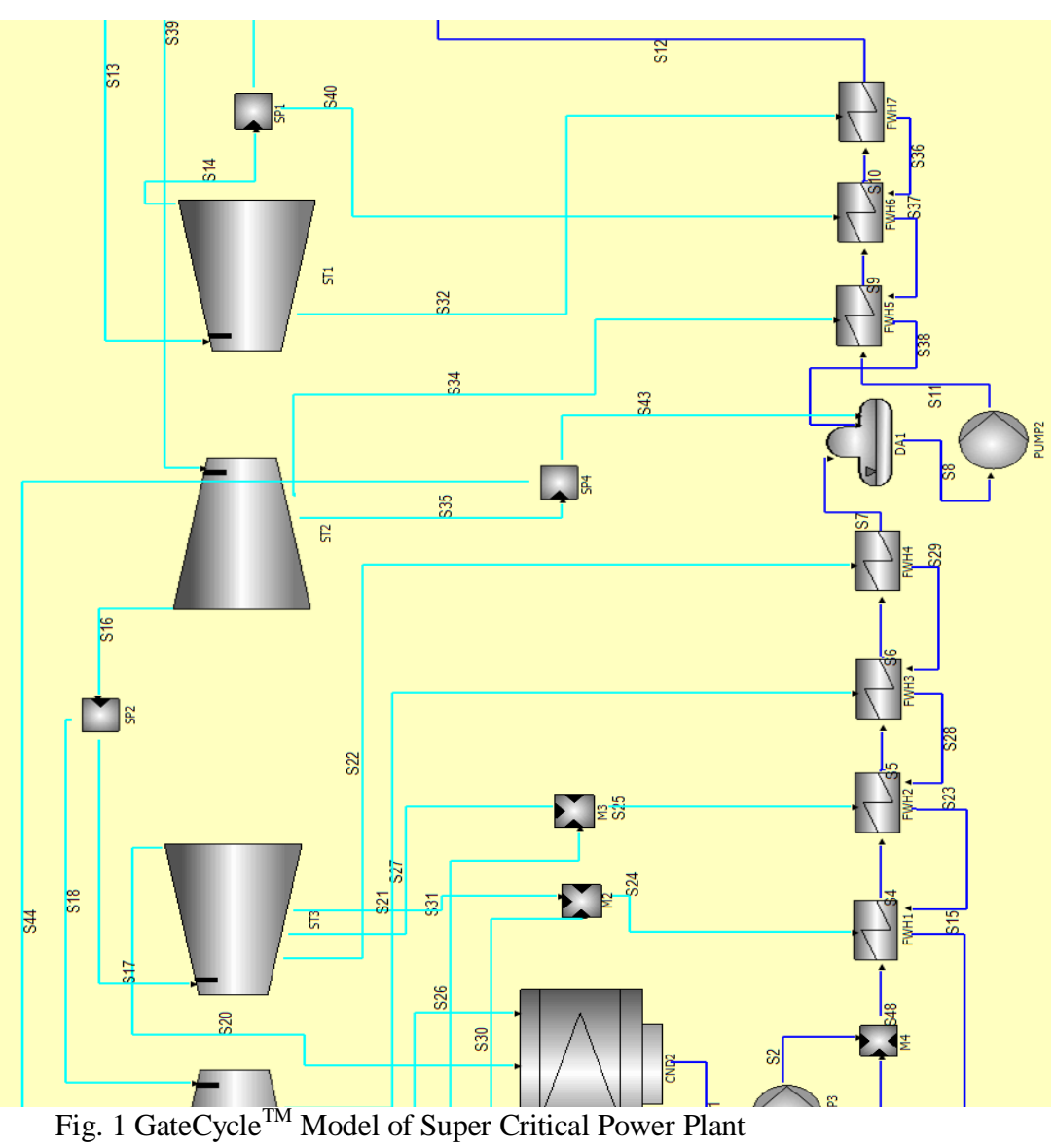


IOSR Journal of Engineering

Apr. 2012, Vol. 2(4) pp: 692-696

\section{RESULT OBTAINED}

The results which obtained from the GateCycle ${ }^{\mathrm{TM}}$ are as given below table.

Table-2 Output Data

\begin{tabular}{|l|c|c|}
\hline \multicolumn{1}{|c|}{ Variable } & Output values & Unit \\
\hline Ambient Temperature & 288 & ${ }^{\circ} \mathrm{K}$ \\
\hline Ambient Pressure & 1.0132 & Bar \\
\hline Ambient Relative Humidity & 0.6 & \\
\hline Ambient Specific Humidity & 0.0063 & $\mathrm{~kW}$ \\
\hline Net Cycle Power & 709735.6 & $\mathrm{kcal} / \mathrm{kW}-\mathrm{hr}$ \\
\hline Net Cycle Lower Heating Value (LHV) Efficiency & 42.7632 & $\mathrm{~kJ} / \mathrm{hr}$ \\
\hline Net Cycle Lower Heating Value (LHV) Heat Rate & 2010.32 & $\mathrm{~kW}$ \\
\hline Total Lower Heating Value (LHV) Fuel Cons. & $5.9747 \mathrm{E} 09$ & $\mathrm{~kW}$ \\
\hline Net Steam Cycle Power & 709735.6 & $\mathrm{~kW}$ \\
\hline ST Shaft Power & 743291.2 & $\mathrm{~kW}$ \\
\hline ST Generator Losses & 14865.81 & $\mathrm{~kW}$ \\
\hline Steam Cycle BOP Losses & 18689.81 & \\
\hline ST Generator Output & 728425.4 & $\mathrm{kcal} / \mathrm{kW}-\mathrm{hr}$ \\
\hline Adjusted Cycle Lower Heating Value (LHV) Efficiency & 42.7632 & $\mathrm{~kW}$ \\
\hline Adj. Cycle Lower Heating Value (LHV) Heat Rate & 2010.32 & 728425.4 \\
\hline Gross Power of Turbine Cycle & & \\
\hline
\end{tabular}

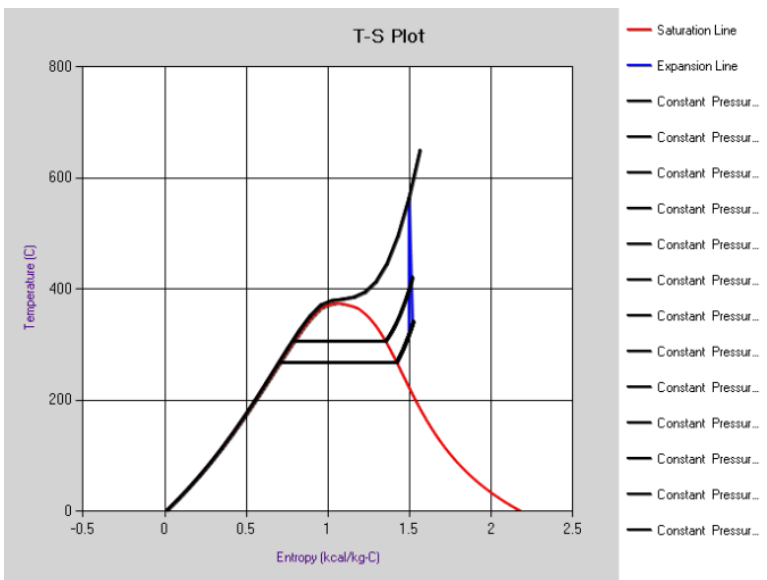

Fig.2 T-S Diagram for ST-1

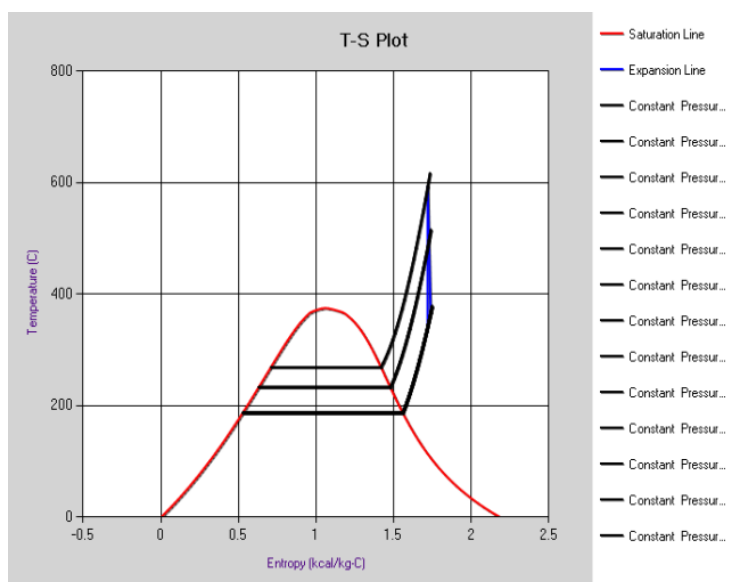

Fig.3 T-S Diagram for ST-2 


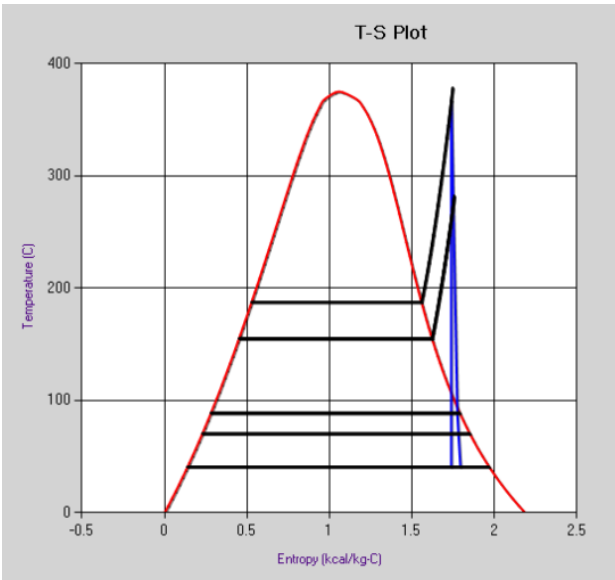

Fig.4 T-S Diagram for ST-3

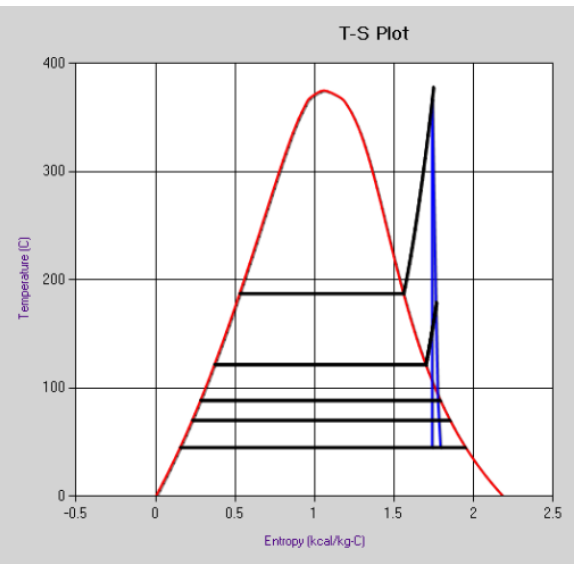

- Saturation Line

- Expansion Line

- Constant Pressur.

- Constant Pressur.

- Constant Pressur

- Contant Pressur

— Constant Pressur

- Contant Pressur

- Constant Pressur

- Constant Pressur

- Constant Pressur

- Constant Pressur-

- Constant Pressu-

- Constant Pressur

- Constant Pressur..

Fig.5 T-S Diagram for ST-4

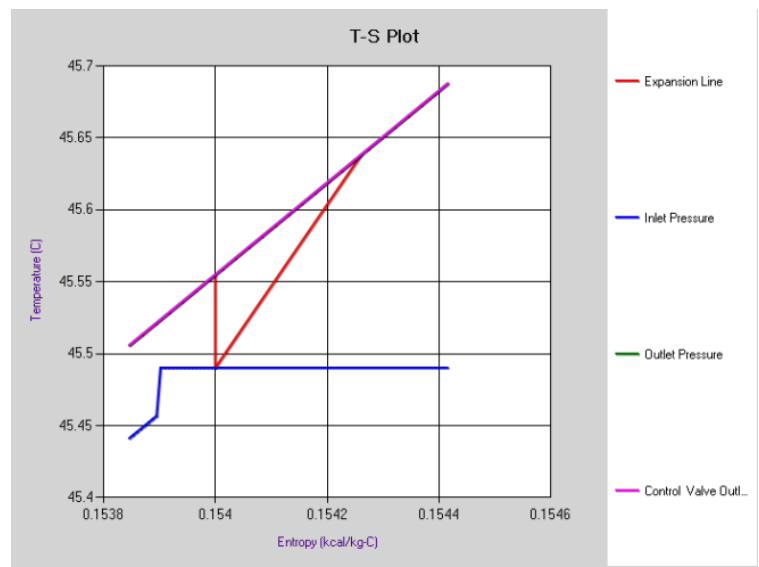

Fig. 6 T-S diagram for PUMP1

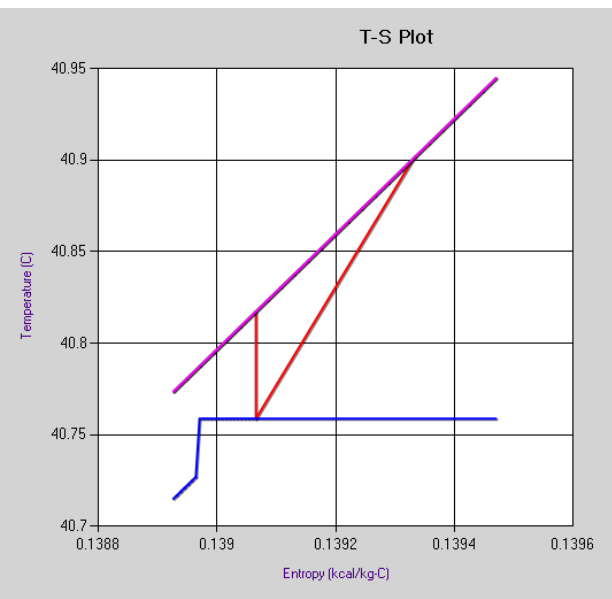

—Expansion Line

Fig. 7 T-S Diagram for PUMP3

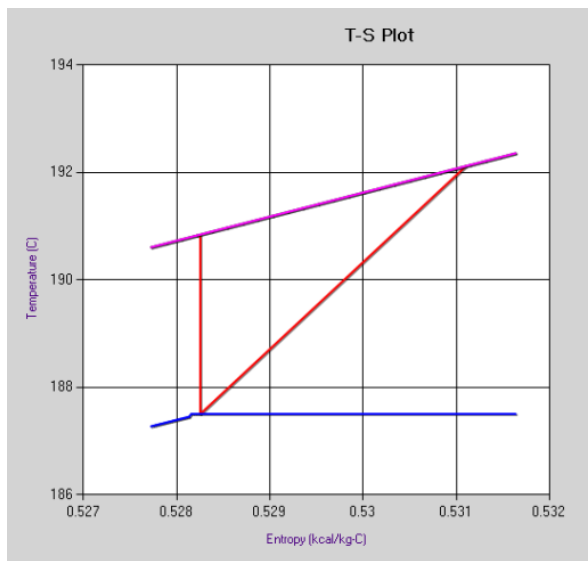

Fig. 8 T-S Diagram for PUMP2

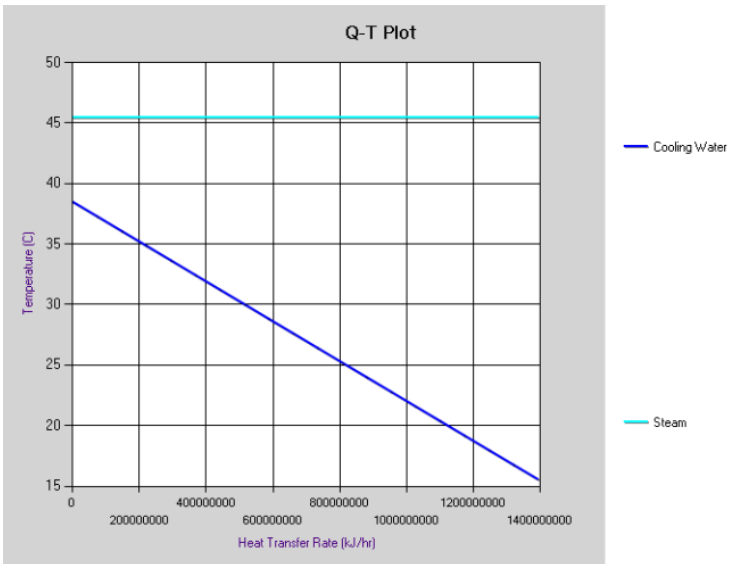

Fig. 9 Q-T Diagram for CND1 


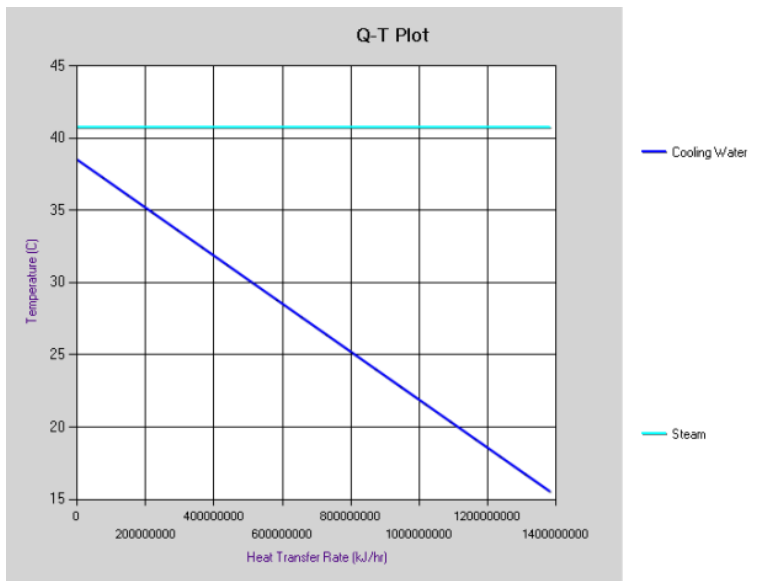

Fig. 10 Q-T Diagram for CND2

\section{CONCLUSION}

This paper describes performance of super critical power plant with help of GateCycle ${ }^{\mathrm{TM}}$ software. The method has been tested by comparing its results with the original results of the plant and these results are very close to the original results and this match very nearly. Table 1 shows the input parameters for the super critical plant and Table 2 shows the results obtained from the GateCycle ${ }^{\mathrm{TM}}$. Fig.2 to fig. 10 shows various charts of different components.

\section{ACKNOWLEDGEMENTS}

I am deeply grateful to L\&T-S\&L for giving me such an opportunity and providing the required data and for allowing use the GateCycle ${ }^{\mathrm{TM}}$ software. . I also owe deep appreciation to and Mr. Salil Kelkar for his tremendous guidance and discussions. I would also like to thank Mr. Alkesh M. Mavani for his patient assistance, support and guidance.

\section{REFERENCES}

1. B. Seyedam, "Computer Simulation of a combined cycle power plant", Heat Recovery System \& CHP VOL. 15, NO.7, pp. 619-630, 1995

2. General Electric Energy "Gate Cycle", Inc. 20042010.

3. Black and Veatch "Power Plant Engineering", Springer Science and Business Media, Inc., 1996 P.No.341-347

4. Blank, "Subcritical versus Supercritical Steam Cycles", New Coal -Fired Unit, Jan. 2006

5. www.ge.com/energy

6. http://www.worldbank.org/html/fpd/em/supercritical/ supercritical.htm 